\title{
KLASIFIKASI KUALITAS KAYU KELAPA MENGGUNAKAN ARSITEKTUR CNN
}

\author{
${ }^{1}$ Nurul Fathanah Mustamin, ${ }^{2}$ Yuslena Sari, ${ }^{3}$ Husnul Khatimi \\ 1,2,3Program Studi Teknologi Informasi, Fakultas Teknik, \\ Universitas Lambung Mangkurat \\ Jl. Brigjen H. Hasan Basri, Pangeran, Kec. Banjarmasin Utara, Kota Banjarmasin, \\ Kalimantan Selatan 70123 \\ Email : 2yuzlena@ulm.ac.id
}

\begin{abstract}
The increase in the export volume of coconut logs, which are materials that can efficiently substitute for conventional wood, demands that the quality of coconut wood classified quickly. However, due to the limitations of a grader as a human being, it is necessary to have assistance from machines or technology that can classify coconut wood quickly. Techniques that used for rapid classification can use computer visualization. Convolutional Neural Network (CNN) with the right architecture makes this method able to recognize and detect objects well, which influenced by computerized factors, large datasets, and techniques to train deeper networks. This study uses five types of CNN architecture, AlexNet, GoogLeNet, ResNet101, ResNet18, and ResNet50. The research results obtained for the classification of the quality of coconut wood using images show that the GoogLeNet architecture has the best classification performance among other architectures. GoogLeNet gets result with an average accuracy of $84.89 \%$ in each layer, followed by RestNet101 architecture with an average accuracy of $78.41 \%$, RestNet50 with an average accuracy of $77.18 \%$, RestNet18 with an average accuracy of $72.94 \%$ and the lowest accuracy performance among other architectures obtained by AlexNet with an average accuracy of $65.84 \%$.
\end{abstract}

Keywords: Classification, Coconut Wood, Computer Visualization Techniques, CNN

\begin{abstract}
Abstrak
Meningkatnya volume ekspor kayu kelapa yang merupakan bahan pengganti kayu konvensional secara efisien menuntut klasifikasi kualitas kayu kelapa dengan cepat. Namun karena keterbatasan seorang grader sebagai manusia maka diperlukan bantuan mesin atau teknologi yang dapat mengklasifikasikan kayu kelapa dengan cepat. Teknik yang dapat digunakan untuk klasifikasi cepat dapat menggunakan teknik visualisasi komputer. Convolutional Neural Network (CNN) dengan arsitektur yang tepat menjadikan metode ini mampu mengenali dan mendeteksi objek dengan baik, yang sebagian besar dipengaruhi oleh faktor komputerisasi, dataset yang besar, dan teknik untuk melatih jaringan yang lebih dalam. Penelitian ini menggunakan lima jenis arsitektur CNN yaitu, AlexNet, GoogLeNet, ResNet101, ResNet18, dan ResNet50. Hasil penelitian yang diperoleh untuk klasifikasi kualitas kayu kelapa menggunakan citra menunjukkan bahwa arsitektur GoogLeNet memiliki performansi klasifikasi terbaik diantara arsitektur lainnya. GoogLeNet mendapatkan hasil dengan rata-rata akurasi 84,89\% pada setiap lapisan, disusul arsitektur RestNet101 dengan akurasi rata-rata 78,41\%, RestNet50 dengan akurasi rata-rata 77,18\%,
\end{abstract}


RestNet18 dengan akurasi rata-rata $72,94 \%$ dan kinerja akurasi terendah di antara arsitektur lainnya diperoleh AlexNet dengan akurasi rata-rata 65,84\%.

Kata kunci: Klasifikasi, Kayu Kelapa, Teknik Visualisasi Komputer, CNN

\section{PENDAHULUAN}

Kelapa merupakan tanaman yang setiap bagiannya memiliki banyak manfaat. Kepala Badan Karantina Pertanian, Ali Jamil, Ph.D., mengatakan bahwa hampir seluruh bagian kelapa telah diekspor, mulai dari daging kelapa, air kelapa, tempurung kelapa, sabut kelapa sampai batang kelapa juga telah diekspor [1]. Batang kayu kelapa telah dikenal sebagai bahan pengganti kayu konvensional untuk membuat bangunan maupun furniture atau bahan kerajinan dengan kualitas yang baik [2][3], tetapi karena elastisitas dari kayu kelapa sangat tinggi maka perlu penanganan khusus untuk menggunakannya.

Pemilihan kayu kelapa berkualitas dapat ditentukan menggunakan tingkat kerapatannya, semakin padat maka kualitas kayu tersebut semakin baik. Selain itu, penentuan kualitas kayu kelapa juga dapat terlihat dari warna dan ukuran dari pola bundelnya, bundel yang berukuran lebih besar dan berwarna lebih gelap akan menghasilkan kayu dengan kualitas yang lebih baik. Proses pemilihan bahan kayu kelapa biasanya dilakukan oleh pakar secara manual (konvensional), oleh karena itu kualitas kayu kelapa tergantung pada keahlian ataupun pengalaman seorang penguji (grader). Seorang grader yang menguji contoh (sample) kayu kelapa secara manual akan mengalami kesulitan jika bahan sampel uji yang akan dilakukan berjumlah banyak sebab keterbatasannya sebagai manusia [4].

Untuk membantu pengujian sampel kayu kelapa dapat dilakukan dengan menggunakan teknologi visualisasi komputer, ilmu yang memungkinkan mesin untuk belajar melihat dan mengidentifikasi serta mengekstrak informasi dari sebuah objek untuk menyelesaiakan tugas tertentu, dengan menentukan terlebih dahulu variabel-variabel yang digunakan untuk menganalisa tekstur dari gambar bundel kayu kelapa tersebut [5]. Analasis ini bertujuan agar parameter yang digunakan untuk melakukan klasifikasi objek penelitian dapat diketahui dengan mengaitkannya dengan fitur dari objek tersebut [6].

Ilmu visualisasi komputer memiliki beberapa pendekatan, diantaranya pendekatan dengan menggunakan Jaringan Syaraf Tiruan (JST), dimana pendekatan ini bekerja layaknya kinerja otak manusia yang kemudian dikembangkan lebih lanjut dalam Deep Learning. Metode Deep Learning yang memberikan hasil spesifik dan signifikan adalah metode Convolutional Neural Network (CNN) [7]. CNN merupakan salah satu metode yang dapat mengenali dan mendeteksi objek dengan baik yang sebagian besar dipengaruhi oleh faktor komputerisasi, dataset yang besar serta teknik untuk melatih jaringan lebih dalam [8]. Tetapi ada satu kekurangan dari metode CNN yaitu proses pelatihan data yang memerlukan waktu lama. Untuk itu pemilihan arsitektur yang tepat diperlukan untuk mendapatkan hasil dengan waktu pelatihan lebih cepat.

Berbagai penelitian tentang teknik pengujian kualitas kayu menggunakan teknologi visualisasi telah dilakukan. Penelitian oleh Ratri Dwi Atmaja et al., menggunakan metode Backpropagation untuk mendeteksi jenis kayu. Penelitian 
ini memberikan hasil akurasi sebesar $82,8 \%$ untuk pengenalan objek kayu dari citra furniture dengan pengenalan pola pada citra tersebut [9]. Penelitian lain mengenai deteksi kayu dilakukan oleh Husnul Khatimi dan Yuslena Sari. Penelitian ini menggunakan metode Genetic Algorithm untuk menentukan kualitas kayu kelapa berdasarkan dari tekstur kepadatan kayu kelapa dan mendapatkan hasil akurasi tertinggi 79,21\% dengan menggunakan parameter GLCM pada sudut $45^{\circ}$ dan Distance 1 [10]. Penelitian lain menggunakan objek 10 jenis kayu dilakukan oleh Hendriyana et al., dengan metode Convolutional Neural Network (CNN) serta arsitektur Mobilenet. Hasil penelitian yang dilakukan menunjukkan akurasi sebesar 93,3\% untuk data ujinya.

Berdasarkan latar belakang tersebut, penelitian ini akan menerapkan metode Convolutional Neural Network dengan beberapa jenis arsitektur untuk mendapatkan jenis klasifikasi kayu kelapa.

\section{METODOLOGI PENELITIAN}

\subsection{Tahapan Penelitian}

Tahapan dari penelitian kualitas kayu kelapa berdasarkan kepadatannya ini dilakukan dengan identifikasi masalah dimana pada tahap ini dipelajari teori-teori tentang kualitas dari batang kayu kelapa, metode ekstraksi dan klasifikasi menggunakan CNN dan SVM. Ekstraksi fitur untuk setiap layer CNN pada citra pola kayu kelapa menggunakan 5 Arsitektur CNN yaitu Alexnet, GoogLeNet, Resnet101, Resnet18 dan Resnet50. Selanjutnya dilakukan proses klasifikasi jenis kayu kelapa menggunakan SVM dengan kernel RBF.

Tahap Selanjutnya yaitu pengumpulan data berupa gambar dari potongan kayu kelapa secara melintang sehingga terlihat pola titik-titik vascular pada batang kayu kelapa tersebut (Gambar 1-3). Pengambilan gambar atau citra dari kayu kelapa ini dilakukan dengan menggunakan bantuan kamera Canon 550D dimana jarak antara kamera dan objek penelitian (Kayu Kelapa) berjarak 1 Meter di bagian depan kamera. Bagian contoh (sample) kayu kelapa diperoleh pada daerah lahan basah Kalimantan Selatan.

Tahapan Selanjutnya yaitu proses data awal atau preprocessing, dimana data-data citra sampel kayu kelapa yang telah dikumpulkan pada tahap sebelumnya akan diproses untuk mendapatkan ukuran citra yang seragam untuk semua data dengan ukuran 255x255 piksel (Gambar 4) dengan menggunakan bantuan aplikasi Photoshop. Setelah itu tahap berikutnya dilakukan perancangan sistem menggunakan software Matlab. 


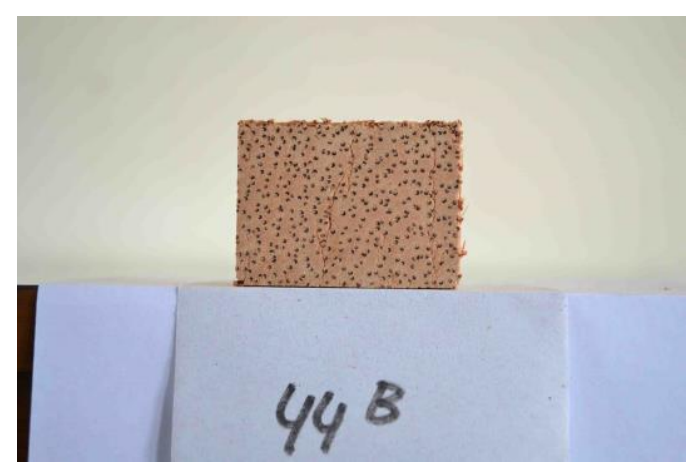

Gambar 1 . Kayu Kelapa dengan Kerapatan Rendah

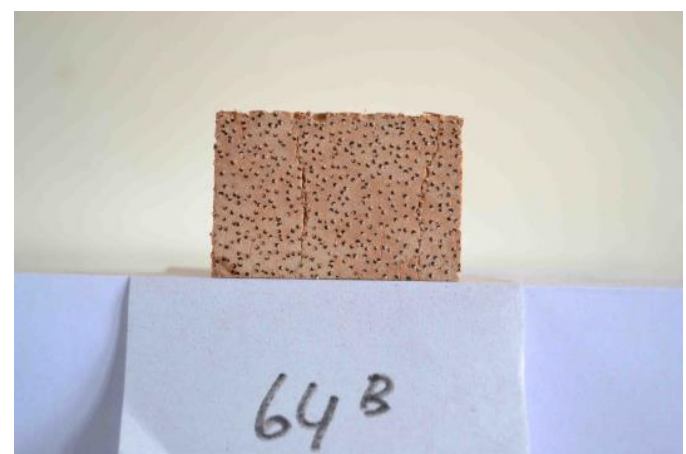

Gambar 2. Kayu Kelapa dengan Kerapatan Sedang

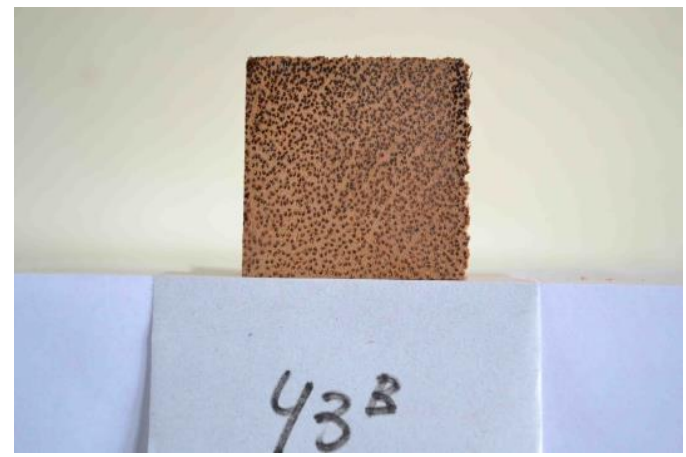

Gambar 3. Kayu Kelapa dengan Kerapatan Tinggi

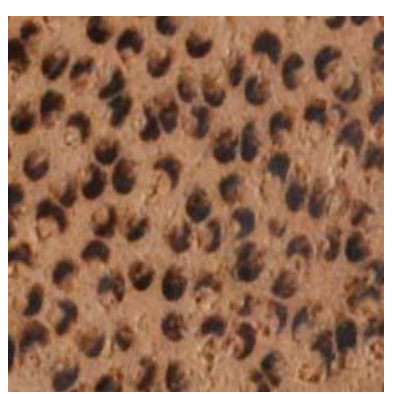

Gambar 4. Hasil Preprocessing Citra Kayu Kelapa 


\subsection{Dasar Teori}

\subsubsection{Kayu Kelapa}

Kayu kelapa atau dalam bahasa latin bernama Cocos Nucifera, merupakan salah satu kayu yang banyak digunakan sebagai bahan untuk membangun konstruksi, kayu kelapa adalah bahan alami yang memiliki sifat unik dan memerlukan pertimbangan lingkungan, pasokan, logistik dan konstruksi khusus. Batang kayu kelapa memiliki tingkat kepadatan yang berbeda. Kayu keras dan kayu lunak ditunjukkan oleh kepadatan dari pusat batang ke arah luar dan dari bagian bawah batang ke arah atas. Ini karena kayu yang terbentuk di setiap penampang biasanya tumbuh lebih lambat dan terdiri dari sel-sel dengan dinding yang lebih tebal. Ada 3 jenis klasifikasi kayu kelapa berdasarkan kepadatan pola bundel, yaitu Rendah, Sedang dan Tinggi.

\subsubsection{Convolutional Neural Network (CNN)}

Convolutional Neural Network (CNN) adalah metode yang muncul pertama kali dengan arsitektur LeNet (Gambar 5) pada tahun 1998. Pada saat itu metode ini belum mendapatkan perhatian dan kurang sukses dikalangan para peneliti karena terbatasnya dataset ujicoba, komputer yang digunakan masih lambat dan berbagai kesalahan dalam penerapan fungsi non linear [11]. Selanjutnya pada tahun 2012, AlexNet (Gambar 6) secara siginifikan mengungguli semua kompetitor sebelumnya dan memenangkan ImageNet Large Scale Visual Recognition Challenge (ILSVRC). Jaringan ini memiliki arsitektur yang sangat mirip dengan LeNet oleh Yann LeCun et al. [11] tetapi lebih dalam, dengan lebih banyak filter per lapisan, dan dengan lapisan konvolusional bertumpuk terdiri dari total 25 layer dengan 8 convolutional layer dan 60 juta parameter [12].

Setahun selanjutnya pada tahun 2013, kompetisi tersebut dimenangkan lagi oleh arsitektur CNN yaitu ZFNet (Gambar 7). Berikutnya pemenang kompetisi ILSVRC 2014 adalah GoogLeNet (atau Inception V1) dari Google (Gambar 8). Jaringan ini menggunakan CNN yang terinspirasi oleh LeNet tetapi menerapkan elemen baru yang disebut Inception Module. Jaringan ini menggunakan normalisasi batch, distorsi gambar dan RMSprop. Modul ini didasarkan pada beberapa konvolusi yang sangat kecil untuk mengurangi jumlah parameter secara drastis [13]. Runner-up kompetisi ILSVRC 2014 ini dijuluki VGGNet (Gambar 9) oleh komunitas dan dikembangkan oleh Simonyan dan Zisserman. VGGNet terdiri dari 16 lapisan konvolusional dan sangat menarik karena arsitekturnya yang sangat seragam. Mirip dengan AlexNet, hanya konvolusi 3x3, tetapi banyak filter [14]. Pada ILSVRC 2015 diperkenalkan lagi jenis CNN dengan arsitektur baru yang dikenal dengan nama Residual Neural Network (ResNet) oleh Kaiming He et al., dengan sebuah fitur baru yaitu "skip connection" dan heavy batch normalization (Gambar 10). Berkat teknik ini, mereka dapat melatih Neural Network dengan 152 lapisan namun tetap memiliki kompleksitas yang lebih rendah daripada VGGNet.

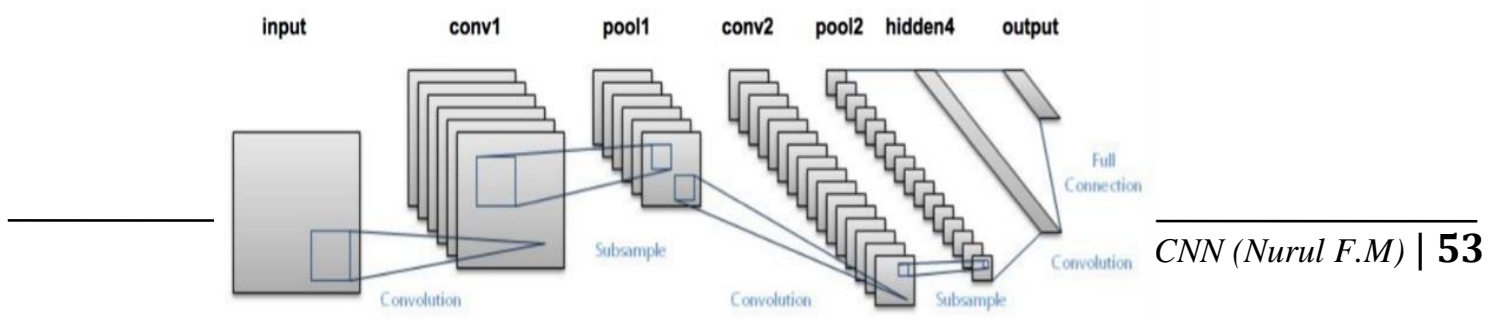


Gambar 5. LeNet [15]

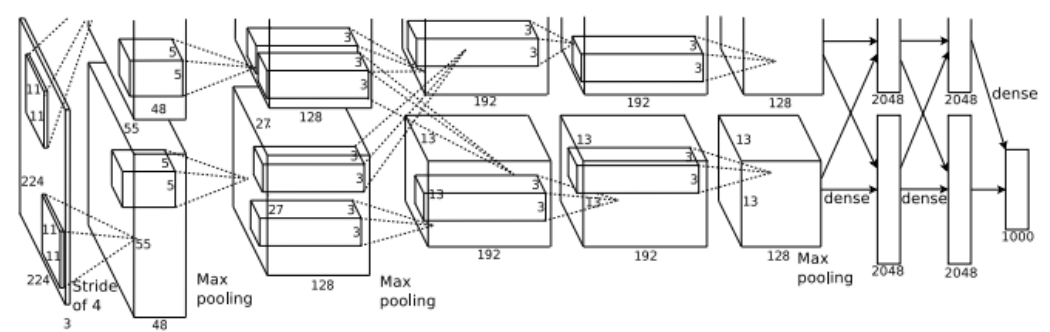

Gambar 6. AlexNet [12]

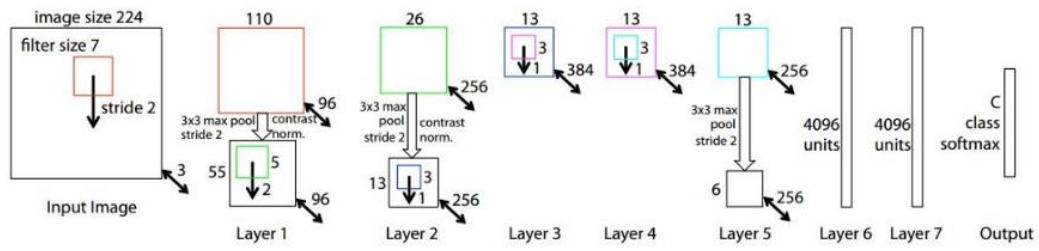

Gambar 7. ZFNet [16]

(1)

Convolution

Pooling

Softmax

Other

Gambar 8. GoogLeNet [17]
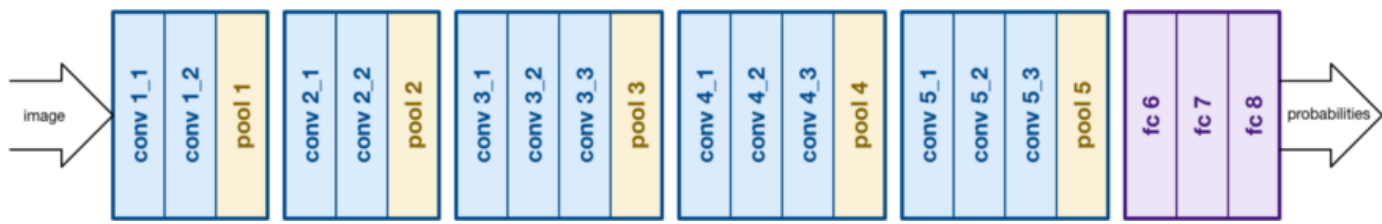

Gambar 9. VGGNet [18] 

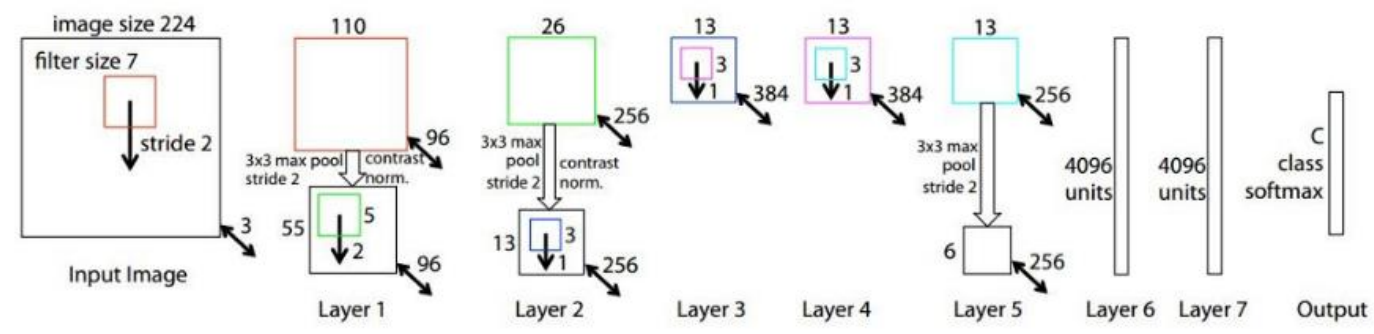

Gambar 10. ResNet[18]

\section{HASIL DAN PEMBAHASAN}

Pada penelitian ini dilakukan klasifikasi dataset citra kayu kelapa sebanyak 174 gambar kayu kelapa yang terbagi atas tiga kelas yaitu Kelas A (Kerapatan Rendah), Kelas B (Kerapatan Sedang) dan Kelas C (Kerapatan Tinggi). Dataset tersebut sebelumnya dilakukan klasifikasi seara manual oleh beberapa orang yang memiliki keahlian dalam menilai kualitas tekstur dari kayu kelapa. Hal ini dilakukan supaya mesin (komputer) dapat belajar bagaimana mendeteksi dan mengklasifikasi kayu kelapa secara benar sesuai kenyataannya.

Hasil akurasi klasifikasi citra kayu kelapa untuk arsitektur CNN dengan layernya dapat dilihat pada Tabel 1 dan Gambar 11. Convolutional Layer menggunakan filter 3x3 dengan jumlah dimensi bertambah di setiap layernya. Ekstraksi fitur menggunakan arsitektur Convolutional Neural Network (CNN) pada setiap layernya menghasilkan 170 fitur. Kemudian setting mini-batch size 32. Jadi nanti data dibagi jadi 10, dimana tiap bagian layer ada 32 data sehingga tiap epoch ada 10 iterasi (forward dan backward).

Tabel 1. Hasil Akurasi Citra Kayu Kelapa Menggunakan CNN

\begin{tabular}{lc}
\hline \multicolumn{1}{c}{ Arsitektur CNN } & Rata- Rata Akurasi \\
\hline AlexNet & $65.84 \%$ \\
GoogLeNet & $84.89 \%$ \\
ResNet101 & $78.41 \%$ \\
ResNet18 & $72.94 \%$ \\
RestNet50 & $77.18 \%$ \\
\hline
\end{tabular}




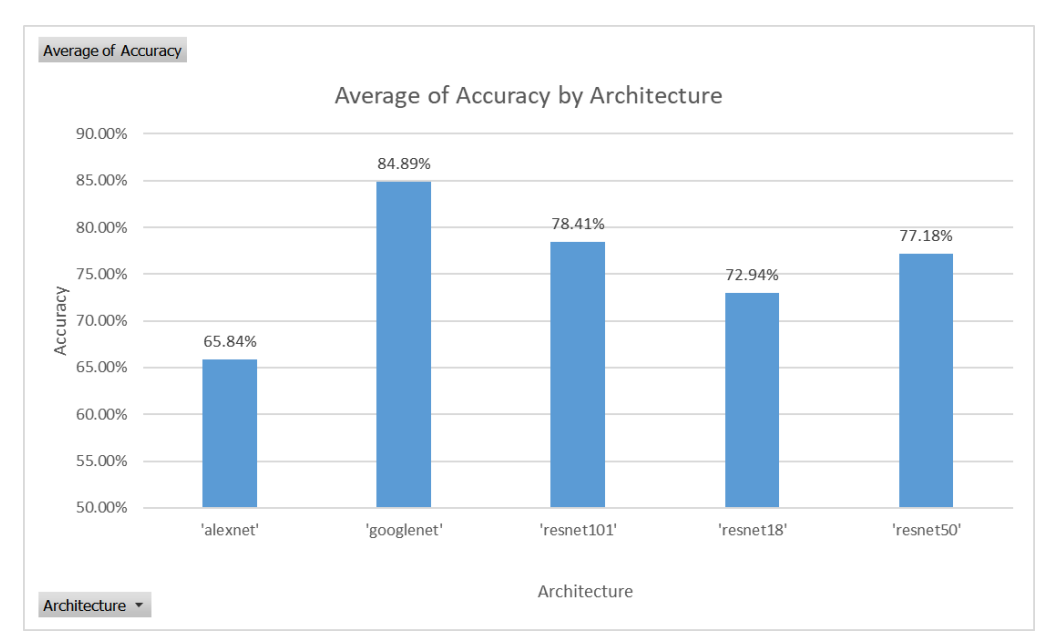

Gambar 11. Rata-Rata Akurasi Arsitektur CNN

Selain akurasi, hasil performa waktu yang digunakan untuk proses klasifikasi citra kayu kelapa menggunakan CNN dapat dilihat pada Tabel 2 dan Gambar 12. Dimana waktu yang digunakan untuk tiap arsitektur CNN daat dijadikan sebagai dasar pemilihan arsitektur yang tepat untuk otomatisasi pemilihan kualitas kayu kelapa dengan menggunakan citra atau gambar secara cepat.

Tabel 2. Hasil Performa Waktu Running Program Menggunakan Arsitektur CNN

\begin{tabular}{lc}
\hline \multicolumn{1}{c}{ Arsitektur CNN } & Waktu Proses $(\mathrm{m})$ \\
\hline AlexNet & 9,50 \\
GoogLeNet & 52,40 \\
ResNet101 & 120,47 \\
ResNet18 & 22,08 \\
RestNet50 & 60,40 \\
\hline
\end{tabular}

Sum of Time (minute)

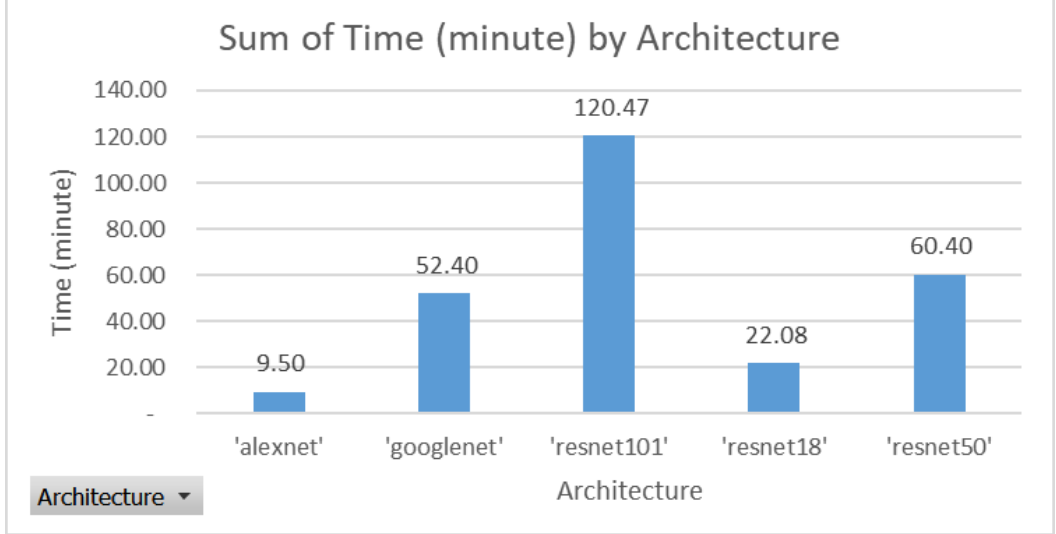

Gambar 12. Total Waktu Proses Arsitektur CNN 
Dari hasil yang dilakukan untuk klasifikasi kualitas kayu kelapa menggunakan citra atau gambar menunjukkan bahwa arsitektur GoogLeNet memiliki performa klasifikasi paling baik diantara arsitektur lainnya dengan perolehan rata-rata akurasi di setiap lapisannya (layer) sebanyak $84,89 \%$, diikuti dengan arsitektur RestNet101 dengan rata-rata akurasi 78,41\%, Restnet50 dengan rata-rata akurasi $77,18 \%$, RestNet18 dengan rata-rata akurasi $72,94 \%$ dan performa akurasi paling rendah diantara arsitektur lainnya didapatkan oleh AlexNet dengan rata-rata akurasi sebesar 65,84\%.

Tetapi, untuk performa waktu proses klasifikasi kualitas kayu kelapa menggunakan citra, arsitektur AlexNet menyelesaikan klasifikasi dengan catatan waktu 9,50 menit tiap layer menjadikan arsitektur ini tercepat dalam melakukan klasifikasi dibandingkan dengan arsitektur lainnya. Arsitektur selanjutnya yang memiliki waktu tercepat yaitu ResNet18 dengan catatan waktu 22,08 Menit, kemudian GoogleNet dengan catatan waktu 52,40 menit, dilanjutkan arsitektur ResNet dengan waktu proses 60,40 menit dan terakhir arsitektur ResNet101 dengan waktu proses 120,47 menit. Untuk lebih jelas mengenai perbandingan ini, maka perhatikan Gambar 13.

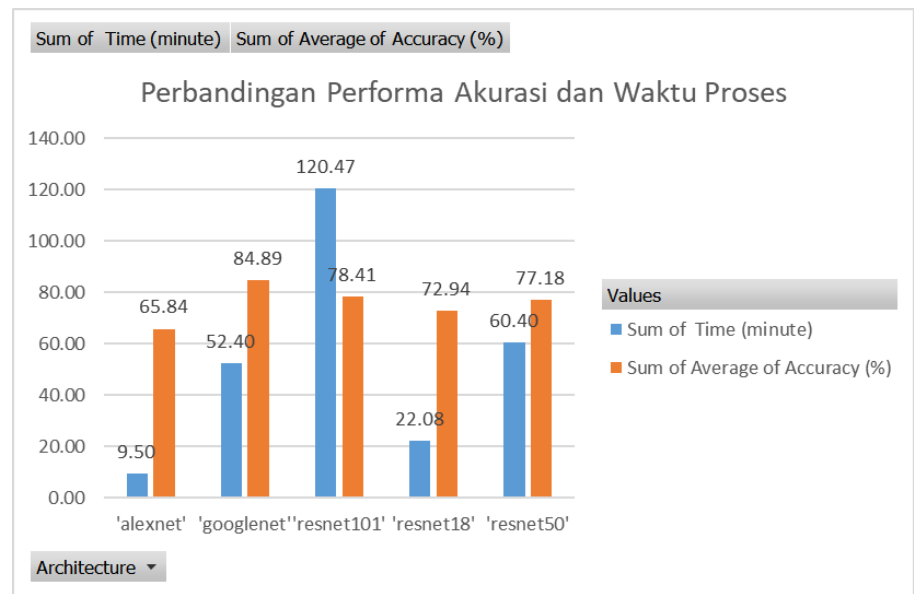

Gambar 13. Perbandingan Rata-Rata Akurasi dan Waktu Proses CNN

\section{SIMPULAN}

Telah dilakukan klasifikasi kualitas kayu kelapa menggunakan citra atau gambar dengan ukuran 255x255 piksel untuk tiap gambar menggunakan metode CNN dan arsitektur AlexNet, GoogleNet, ResNet101, ResNet18 dan ResNet50. Dari hasil penelitian yang dilakukan didapatkan bahwa metode CNN dengan AlexNet memberikan waktu proses yang cukup rendah dibanding arsitektur yang lain dengan catatan waktu 9.50 menit sedangkan untuk kualitas akurasi rata-rata klasifikasi kayu kelapa ditiap layernya didapatkan oleh arsitektur GoogLeNet dengan rata-rata $84,89 \%$.

\section{UCAPAN TERIMA KASIH}

Ucapan terima kasih sebagai peneliti kami sampaikan untuk Lembaga Penelitian dan Pengabdian Kepada Masyarakat (LPPM) Universitas Lambung Mangkurat yang 
sudah mendukung serta memberikan biaya untuk terwujudnya penelitian ini melalui DIPA Universitas Lambung Mangkurat Tahun Anggaran 2020 Nomor: 023.17.2.6777518/2020 Tanggal 16 Maret 2020

\section{DAFTAR PUSTAKA}

[1] “Badan Karantina Pertanian.” https://karantina.pertanian.go.id/pers-1015berkualitas-tinggi-industri-olahan-kelapa-tembus-6-benuaberkualitas-tinggiindustri-olahan-kelapa-te.html (accessed Feb. 10, 2021).

[2] J. Balfas, "Perlakuan Resin Pada Kayu Kelapa (Cocos Nucifera)," J. Penelit. Has. Hutan, vol. 25, no. 2, pp. 108-118, 2007.

[3] D. Purwanto, "Finishing Kayu Kelapa (Cocos Nucifera L.) Untuk Bahan Interior Ruangan,” J. Ris. Ind. Has. Hutan, vol. 3, no. 2, pp. 32-37, 2011.

[4] I. Yuwono, R. Pramunendar, P. Andono, and R. A. Subandi, "The Quality Determination Of Coconut Wood Density Using Learning Vector Quantization," vol. 57, pp. 82-87, Nov. 2013.

[5] H. Hendriyana and Y. H. Maulana, "Identification of Types of Wood using Convolutional Neural Network with Mobilenet Architecture," J. RESTI Rekayasa Sist. Dan Teknol. Inf., vol. 4, no. 1, pp. 70-76, 2020.

[6] G. A. Ruz, P. A. Estevez, and C. A. Perez, "A Neurofuzzy Color Image Segmentation Method For Wood Surface Defect Detection," For. Prod. J., vol. 55, no. 4, pp. 52-58, 2005.

[7] S. Gasim and Agus Harjoko, "Metode Identifikasi Jenis Kayu Berdasarkan Model Blok Citra Mikroskopis Penampang Melintang," PhD Thesis, Universitas Gadjah Mada, Yogyakarta, 2014.

[8] Fera Flaurensia, Tedy Rismawan, and Rahmi Hidayati, "Pengenalan Motif Batik Indonesia Menggunakan Deteksi Tepi Canny dan Template Matching," Coding J. Komput. Dan Apl., vol. 4, no. 2, 2016.

[9] Ratri Dwi Dkk Atmaja, Achmad Rizal, and Koredianto Usman, "Deteksi Jenis Kayu Citra Furniture Ukiran Jepara Menggunakan JST Backpropagation," Konf. Nas. Sist. Inf. STMIK-STIKOM Bdg., 2012.

[10] Husnul Khatimi and Yuslena Sari, "Otomatisasi Tingkat Kualitas Kayu Kelapa Menggunakan Genetic Algorithm," INFO-Tek., vol. 20, no. 2, pp. 255-264, Desember 2019.

[11] Yann LeCun, Léon Bottou, Yoshua Bengio, and Patrick Haffner, “GradientBased Learning Applied to Document Recognition,” Proc. IEEE, vol. 86, no. 11, pp. 2278-2324, 1998.

[12] Alex Krizhevsky, Ilya Sutskever, and Geoffrey E. Hinton, "Imagenet classification with deep convolutional neural networks," Adv. Neural Inf. Process. Syst., vol. 25, pp. 1097-1105, 2012.

[13] Christian Szegedy, Vincent Vanhoucke, Sergey Ioffe, Jon Shlens, and Zbigniew Wojna, "Rethinking The Inception Architecture for Computer Vision," in Proceedings of The IEEE Conference on Computer Vision and Pattern Recognition, 2016, pp. 2818-2826.

[14] Karen Simonyan and Andrew Zisserman, "Very Deep Convolutional Networks for Large-Scale Image Recognition," ArXiv Prepr. ArXiv14091556, 2014. 
[15] "Papers with Code - LeNet Explained." https://paperswithcode.com/method/lenet (accessed Feb. 10, 2021).

[16] Matthew D. Zeiler and Rob Fergus, "Visualizing and Understanding Convolutional Networks," in European Conference on Computer Vision, 2014, pp. 818-833.

[17] R. Alake, "Deep Learning: GoogLeNet Explained," Medium, Dec. 23, 2020. https://towardsdatascience.com/deep-learning-googlenet-explainedde8861c82765 (accessed Feb. 10, 2021).

[18] S. Das, "CNN Architectures: LeNet, AlexNet, VGG, GoogLeNet, ResNet and more," Medium, Sep. 17, 2019. https://medium.com/analytics-vidhya/cnnsarchitectures-lenet-alexnet-vgg-googlenet-resnet-and-more-666091488df5 (accessed Feb. 10, 2021). 